\title{
CORRIGENDUM
}

\section{RUNX1 mutations in acute myeloid leukemia are associated with distinct clinico-pathologic and genetic features}

VI Gaidzik, V Teleanu, E Papaemmanuil, D Weber, P Paschka, J Hahn, T Wallrabenstein, B Kolbinger, CH Köhne, HA Horst, P Brossart, G Held, A Kündgen, M Ringhoffer, K Götze, M Rummel, M Gerstung, P Campbell, JM Kraus, HA Kestler, F Thol, M Heuser, B Schlegelberger, A Ganser, L Bullinger, RF Schlenk, K Döhner and H Döhner for the German-Austrian Acute Myeloid Leukemia Study Group (AMLSG)

Leukemia (2016) 30, 2282; doi:10.1038/leu.2016.207

Correction to: Leukemia (2016) 30, 2160-2168; doi:10.1038/ leu.2016.126; published online 10 June 2016

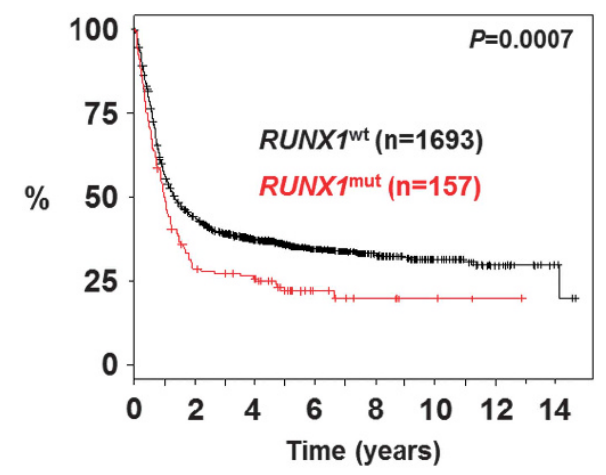

Following the publication of this paper, the authors noted that one of the curves of the Kaplan-Meier plot in Figure $3 \mathrm{~b}$ was labeled incorrectly. In the corrected figure below, RUNX1 $1^{\text {mut }}$ $(n=1693)$ has been corrected to RUNX1 $1^{\mathrm{wt}}(n=1693)$.

Figure $\mathbf{3 b}$. 